\title{
Chondrodysplasia Punctata in a Newborn; Rhizomelic Type: A Case Report
}

\author{
BEGUM SHARIFUN NAHER ${ }^{1}$, MA MANNAN ${ }^{2}$, KHALED NOOR $^{2}$, MD. SHAHIDULLAH $^{3}$
}

\section{Introduction}

Chondrodysplasia punctata refers to a heterogenous group of conditions which share calcific stippling of cartilage and periarticuler soft tissues. Particularly punctuate calcification is seen in the heel in infancy. These disorders differ in clinical features, severity, inheritance pattern and radiological features. Various types like rhizomelic type (autosomal recessive), $\mathrm{X}$ linked dominant type, $X$ linked recessive and ConradiHunerman syndrome are found.

The rhizomelic type: an autosomal recessive disorder of peroxisomal function is usually lethal in infancy and consists of proximal limb shortening, short stature, metaphysial splaying and cupping, multiple joint contracture, flat facies, cataracts, mental retardation, microcephaly and ichthyosiform rash as occasional abnormality $(28 \%)^{1}$. Spranger et al clearly distinguished the rhizomelic type of chondrodysplasia punctata as a separate entity from the other types. Besides the nine personal cases, Spranger et al were able to find 33 additional cases from the literature ${ }^{2}$.

Punctate calcifications may result in delayed endochondral ossification process, growth deficiency and deformity of the bones involved ${ }^{3}$. Chondrodysplasia punctata can be diagnosed by ultrasound during antenatal period ${ }^{4}$. An association with fetal ascitis and poly hydromnios has been reported ${ }^{5}$. Other causes of calcific epiphysial stippling include warferin ${ }^{6}$, phenytoin exposure in pregnancy, several peroxisomal disorders including Zellweger syndrome, Smith Lemli Opitz syndrome ${ }^{7}$, trisomy 18 and $21^{8}$.

\section{Case Report}

A 2 days old male baby, out born, $3^{\text {rd }}$ issue of a non consanguineous parents was delivered by LUCS at 41 weeks of gestation on 19/07/08 at ICMH, Matuail and was referred to the NICU of BSMMU, Dhaka. Baby

1. Associate Professor, Department of Neonatology, SSMC and Mitford Hospital, Dhaka

2. Associate Professor, Department of Neonatology, BSMMU, Dhaka

3. Chairman and Head, Department of Neonatology, BSMMU, Dhaka

Correspondence: Dr. Begum Sharifun Naher was admitted with the complaints of delayed cry and small size of the body and shortening of 4 limbs.

Mother was 28 years old and was on regular antenatal checkup. She took 2 doses of TT. Her pregnancy was uneventful up to 22 weeks of gestation. Then she developed leaking membrane which stopped spontaneously by taking bed rest. She has history of fall 2 times during 23 weeks and 32 weeks of pregnancy. She also complains of decreased volume of liquor in the last month of pregnancy. She gave no history of medication other than vitamins and iron tablets. She was neither hypertensive nor diabetic. There was no history of fever or rash. Her first issue is alive and healthy. She had one abortion. There is no family history of such deformity of limbs but one of her cousins is mentally retarded.

Clinically the baby was mildly icteric and had flat facies. His OFC was $31 \mathrm{~cm}$ which fell below the $3 \mathrm{rd}$ centile and length was $40 \mathrm{~cm}$. Thus he was microcephalic and of short stature. His birth weight was $1700 \mathrm{gm}$. So there was symmetric IUGR. His respiratory rate was $58 / \mathrm{min}$ and regular, heart rate was 138 beats/min. Baby was acyanotic. On auscultation, breath sound was normal, there was no added sound. $1^{\text {st }}$ and $2^{\text {nd }}$ heart sounds were normal but systolic murmur was heard over the precordium mostly marked on the left parasternal region. Abdomen was soft, meconium passed and urinary bladder evacuated. Proximal shortening of upper and lower limbs was obvious (Fig.-1). There was mild flexion deformity of all limbs. No cataract or skin rash was found. The provisional diagnosis was Achondroplasia

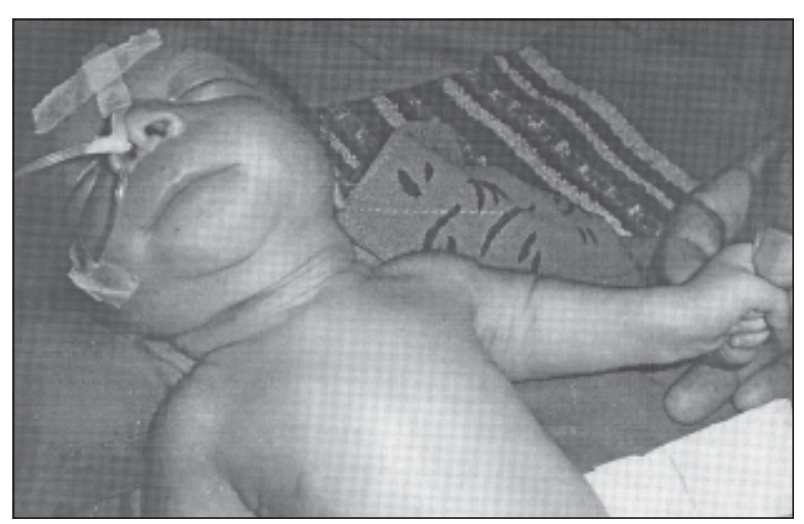

Fig.-1: Photograph showing short upper limb 
with perinatal asphyxia with hypoxic ischaemic encephalopathy (HIE) with symmetric IUGR and low birth weight baby.

Routine laboratory tests were done. $\mathrm{Hb} \%$ was $16 \mathrm{gm} /$ dL, WBC - 14000/cmm, neutrophil-40\%, lymphocyte50\%, monocyte-2\%, eosinophil-4\% and basophil-4\%. Urine R/E was normal, serum bilirubin was $9.5 \mathrm{mg} /$ dL. On radiographic studies we have observed a) symmetrical bilateral proximal shortening of upper and lower limbs (rhizomelic pattern), b) multiple calcification in the epiphyseal cartilage of long bones and ankles, c) metaphyseal splaying, d) punctuate calcification in vertebral bodies, pedicles including the sacrum (Fig2). Doppler echocardiography revealed small VSD (Ventricular Septal Defect) which was in the membranous part of the septum.

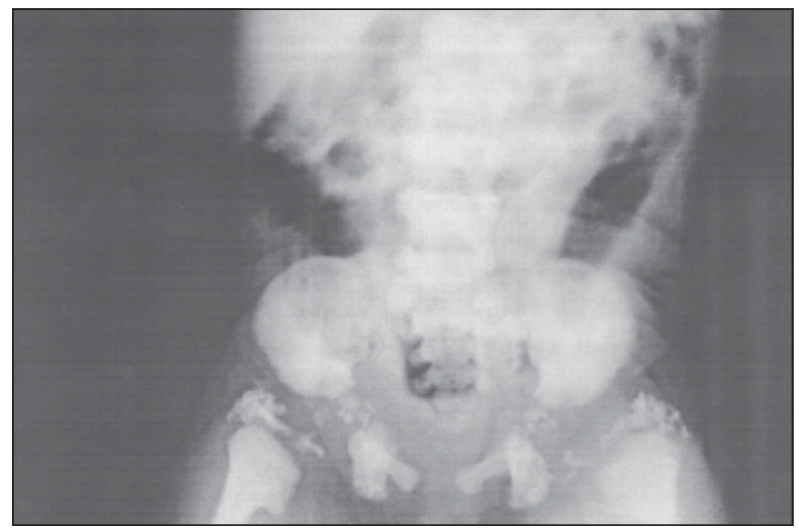

Fig.-2: X-Ray of pelvis showing multiple calcification in the epiphyseal cartilage

\section{Discussion}

Chondrodysplasia punctata (CDP) rhizomelic type is a disorder characterized by skeletal manifestation of proximal shortening of upper and lower limbs with short humerus and femur, short stature, microcephaly, flat facies and cataract ${ }^{1}$. This condition is associated with a loss of specific peroxisomal function. Peroxisomes are subcelluler organelles that play an important role in several metabolic processes. Deficiencies in the peroxisomal enzymes involved in phospholipids synthesis have been found and there is an impairment of phytanic acid oxidation.

The $X$ linked dominant type ${ }^{9}$ thought to be lethal in male, is characterized by asymmetrical skeletal abnormalities with short stature, shortening of long bones, contractures of joints and scoliosis together with alopecia of scalp, abnormal hair and cataracts. An $X$ linked recessive form has been described ${ }^{10}$ in association with a deletion of the terminal short arm of an X chromosome in brothers with epiphyseal stippling, nasal hypoplasia, ichthyosis and mental retardation.

The term Conradi Hunerman syndrome has been applied to an apparently heterogenous group of conditions whose features include asymmetrical short stature, scoliosis, cataract, ichthyotic rash and flat facies with nasal hypoplasia ${ }^{11}$. The patients include some with $\mathrm{X}$ linked dominant, autosomal dominent ${ }^{12}$ and sporadic form ${ }^{13}$.

The autosomal form results from a peroxisomal metabolic disorder ${ }^{14,15}$, the $X$ linked dominant by defects in cholesterol biosynthesis pathway and the $X$ linked recessive results from defective arylsulphatase $\mathrm{E}^{14}$.

Today the CDP diagnosis is made by means of a clinical analysis concomitant with biochemical and radiological findings. Currently rhizomelic type of CDP is diagnosed through clinical features compatible with the syndrome and associated biochemical findings including phytanic acid serum level, screening of plasmalogen synthesis on cultured fibroblast ${ }^{16}$.

It is important to note that patients with the diagnosis of rhizomelic CDP should undergo ambulatorial followup inspite of the current inexistence of specific treatment. Many clinical manifestations, like alopecia, cataract might not be present at the moment of the diagnosis. Other manifestation like punctuate calcifications tend to disappear with aging ${ }^{16}$.

\section{References}

1. Schutgens RBH, Heymans HSA, Wanders RJA. Peroxisomal disorders: a newly recognized group of genetic diseases. Eur J Pediatr 1986; 144: 430-40.

2. Spranger JW, Bidder U, Voelz C. Chondrodysplasia punctata (chondrodysplasia calcificans) 11 . The rhizomelic type. Nuclearmed 1971; 114: 327.

3. Montier GR, messiaen LM, Espeel M. Chondrodysplasia punctata with multiple congenital and new syndrome? Pediatr Radiol 1998; 28: 290-93.

4. Duff P, Harlass FE, Milligan DA. Perinatal diagnosis of Chondrodysplasia punctata by sonography. Obstet Gynecol 1990; 76: 497-500. 
5. Straub W, Zarabi M, Mazer J. Fetal ascitis associated with Conradi's disease (Chondrodysplasia punctata) : Report of a case. JCU 1983; 11: 234-36.

6. Hall JG, Pauli RM, Wilson KM. Maternal and fetal sequence of anti coagulation during pregnancy. Am J Med 1980; 68: 122-40.

7. Gibson R. A case of Smith Lemli Opitz syndrome of multiple congenital anomalies in association with dysplasia epiphysealis punctata. Can Med Assoc J 1965; 92: 574-75.

8. Romero R, Pilu G, Jeanty P. Prenatal diagnosis of congenital anomalies. East Norwalk: Appleton and Lange; 1988.

9. Manzke H, Christopher E, Wiedemann HR. Dominant sex linked inherited Chondrodysplasia punctata. Clin Genet 1980; 17: 97-107.

10. Curry CJR, Magenis RE, Brown M. Inherited Chondrodysplasia punctata due to a deletion of the terminal short arm of an X chromosome. $\mathrm{N}$ Engl J Med 1984; 311: 1010-15.
11. Sprangen JW, Opitz JM, Bidder U. Heterogeneity of Chondrodysplasia punctata . Human genetic 1970; 11: 190-212.

12. Silengo MC, Luzzatti L, Silverman FN. Clinical and genetic aspects of Chondrodysplasia punctata disease. A report of three familial cases and review of literature. J Pediatr 1980; 97: 91117.

13. Sheffield LJ, Danks DM, Mayne V. Chondrodysplasia punctata- 23 cases of a mild and relatively common variety. J Pediatr 1976; 89: 916-23.

14. Kumada S, Hayashi M, Kenmochi J. Lethal form of Chondrodysplasia punctata with normal cholesterol biosynthesis. Am J Med Genet 2001; 98: 250-55.

15. Omobono E, Goetsch W. Chondrodysplasia punctata (Conradi Hunerman syndrome). A Clin report and review of the literature. Minerva Pediatr 1993; 45: 117-21.

16. Pascolat G, Zindelok JL, Abraao KC, Rodrigues FM, Guedes CIM. Rizomalic chondrodysplasia punctata - case report. J Pediatr 2003; 79: 189-92. 